\title{
Effect of stacked sodium bicarbonate loading on repeated all-out exercise
}

\author{
Sebastiaan Dalle ${ }^{1}$, Stefan De Smet ${ }^{1}$, Willem Geuns ${ }^{2}$, Bart Van Rompaye ${ }^{3}$, Peter Hespel ${ }^{1,2}$, \\ Katrien Koppo ${ }^{1}$ \\ ${ }^{1}$ Dept. of Movement Sciences, KU Leuven, Leuven, Belgium \\ ${ }^{2}$ Bakala Academy Athletic Performance Center, KU Leuven, Leuven, Belgium \\ ${ }^{3}$ Dept. of Applied Mathematics, Computer Science and Statistics, UGent, Gent, Belgium
}

\begin{abstract}
The purpose of this study was to evaluate whether $\mathrm{NaHCO}_{3}$, administered via a 9-h stacked loading protocol (i.e. repeated supplementation with small doses in order to obtain a gradual increase in blood $\left[\mathrm{HCO}_{3}^{-}\right]$), has an ergogenic effect on repeated all-out exercise. Twelve physically active males were randomly assigned to receive either $\mathrm{NaHCO}_{3}$ (BIC) or placebo (PL) in a double-blind cross-over design. $\mathrm{NaHCO}_{3}$ supplementation was divided in three identical 3-h cycles: a $6.3 \mathrm{~g}$ bolus at the start, followed by $2.1 \mathrm{~g}$ doses at $+1-\mathrm{h}$ and $+2-\mathrm{h}$, yielding a total $\mathrm{NaHCO}_{3}$ intake of $0.4 \mathrm{~g} \cdot \mathrm{kg}^{-1} \mathrm{BM}$ over $9 \mathrm{~h}$. At the end of each cycle, participants performed 2-min all-out cycling. Capillary blood samples were analysed for $\left[\mathrm{HCO}_{3}^{-}\right], \mathrm{pH}$ and [La']. Pre-exercise blood $\left[\mathrm{HCO}_{3}{ }^{-}\right]$in $\mathrm{PL}$ decreased from $25.6 \pm 0.2 \mathrm{mmol} \cdot \mathrm{L}^{-1}$ in bout 1 to $23.6 \pm 0.2 \mathrm{mmol} \cdot \mathrm{L}^{-1}$ in bout 4 , whilst increasing from $25.5 \pm 0.2$ to $31.2 \pm 0.4 \mathrm{mmol} \cdot \mathrm{L}^{-1}$ in $\mathrm{BIC}$ $(\mathrm{P}<0.05)$. Concomitantly, pre-exercise $\mathrm{pH}$ values gradually decreased in PL (from $7.41 \pm 0.00$ to $7.39 \pm 0.01$ ) and increased in BIC (from 7.41 \pm 0.01 to $7.47 \pm 0.01 ; \mathrm{P}<0.05$ ). Mean power output of the 4 bouts was higher in BIC $(428 \pm 20 \mathrm{~W})$ than in PL $(420 \pm 20 \mathrm{~W} ; \mathrm{P}<0.05)$. The ergogenic effect on repeated all-out exercise occurred in the absence of gastrointestinal distress.
\end{abstract}

Key words: buffer capacity, muscle energetics, sprint performance, cycling

\section{Introduction}

Numerous sports performances consist of repetitive short all-out exercise bouts that require a high fraction of energy input via anaerobic glyco(geno)lysis. This results in the accumulation of lactate anions $\left(\mathrm{La}^{-}\right)$and hydrogen protons $\left(\mathrm{H}^{+}\right)$in muscle cells and in the extracellular space. Some researchers challenge the central role of intramyocellular $\mathrm{H}^{+}$accumulation in muscle fatigue(36). Shortly, it was argued that acidosis cannot be an important contributor to muscle fatigue as 1) some studies observed no temporal correlation between the extent of acidosis and the decline in contractile function(10), 2) muscle fatigue in single murine muscle fibers was little affected by $\mathrm{pH}$ at near-physiological temperatures(5) and 3) decreases in $\mathrm{pH}$ failed to decrease the rate of glycogenolysis/glycolysis during repeated contractions in humans(1). In contrast, others implicated a low cell $\mathrm{pH}$ as one of the fatigue inducing agents during highintensity muscle contractions $(12,31)$. A low intramuscular acidity was reported to reduce crossbridge force, velocity and power(12), and to depress myofibrillar $\mathrm{Ca}^{2+}$ sensitivity(29).

One strategy to attenuate fatigue development during anaerobic exercise is to inhibit $\mathrm{H}^{+}$ accumulation by increasing buffer capacity, for instance via oral $\mathrm{NaHCO}_{3}$ supplementation(25). Indeed, increasing the alkaline reserve prior to exercise enables muscle to produce more $\mathrm{H}^{+}$and $\mathrm{La}^{-}$by increasing the gradient for efflux from the muscle(22). Nevertheless, evidence supporting the ergogenic effect of $\mathrm{NaHCO}_{3}$ in short all-out exercise is equivocal. Literature inconsistencies could partly result from variations in dosage regimen. Doses investigated ranged from 0.1 to $0.5 \mathrm{~g} \mathrm{NaHCO}_{3}$ per $\mathrm{kg}$ body mass $(\mathrm{BM})$, with the optimal dosage for anaerobic 
performances of $\sim 1$-min being $0.35 \mathrm{~g} \cdot \mathrm{kg}^{-1} \mathrm{BM}(26)$. Furthermore, Saunders et al. (2014) showed that there is large inter-individual variability in the ergogenic response to sodium bicarbonate(32). This could be related to differences in time to peak alkalosis. Therefore, the timing of $\mathrm{NaHCO}_{3}$ administration prior to exercise can be individualized to ensure that blood $\left[\mathrm{HCO}_{3}{ }^{-}\right]$for each individual peaks at exercise onset(16). Unfortunately, predetermination of the time to peak blood $\left[\mathrm{HCO}_{3}^{-}\right]$is rather time consuming as it requires multiple visits to the laboratory. Also, the need of sophisticated devices raises additional costs. Furthermore, one single $\mathrm{NaHCO}_{3}$ dose prior to the first of multiple exercise bouts is insufficient to increase blood $\left[\mathrm{HCO}_{3}{ }^{-}\right]$prior to all bouts(37). Therefore, prolonging increased bicarbonate levels throughout a performance day might be a more straightforward strategy.

A recurring issue with $\mathrm{NaHCO}_{3}$ supplementation is the gastrointestinal (GI) distress experienced by many athletes(7). These GI problems, mostly stomach cramping and diarrhea, may counteract the beneficial effect of induced alkalosis and preclude improvements in performance. It was reported that the incidence of GI distress is most prominent 90-min after ingestion(8) and that the complaints aggravated with doses above $0.3 \mathrm{~g} \cdot \mathrm{kg}^{-1} \mathrm{BM}(26)$. To reduce the risk of GI distress during a competitive event, some researchers experimented with chronic loading and administered $\mathrm{NaHCO}_{3}$ over several days or weeks $(11,24)$. The advantage of such an approach is that blood buffering capacity can be build up during the days before the race, thereby avoiding GI problems due to acute high-dose $\mathrm{NaHCO}_{3}$ intake prior to exercise. However, this might be accompanied by a diminished $\mathrm{HCO}_{3}{ }^{-}$production by the kidneys on the long term and therefore abolish the physiological advantage. Stacked $\mathrm{NaHCO}_{3}$ loading during the day of performance(s), on the other hand, might be of interest in many sport disciplines such as rowing, swimming, track cycling, athletic events, as their competition structure involves repeated qualification rounds throughout the day, which may gradually deplete the alkaline reserve and impair the performance in the final medal event.

Therefore, it is important to design a $\mathrm{NaHCO}_{3}$ intake protocol that meets the intermittent structure of the aforementioned competition schedules, yet at the same time avoiding GI symptoms. However, research supporting such a gradual administration schedule is lacking. The aim of the present study is to assess the effect of stacked $\mathrm{NaHCO}_{3}$ loading on blood acidbase balance, GI distress, and performance during a 9-h time window in which several distinct maximal exercise bouts are performed.

\section{Materials and Methods}

\section{Participants}

Twelve physically active males (mean \pm SD; age: $21 \pm 1 \mathrm{yr}$; height: $1.81 \pm 0.10 \mathrm{~m}$; BM: $74.4 \pm 9.9 \mathrm{~kg}$ ) volunteered to participate in this study. They were fully informed about the aim and the protocol of the study and signed a written informed consent approved by the Ethics Committee Research UZ/KU Leuven. Research was conducted in accordance with international standards for ethics in sport and exercise(18). A medical examination was performed by a GP prior to the start of the study to exclude participants with contra-indications for participation in strenuous exercise. All participants were non-smokers. They trained between 5-8h/week in a variety of disciplines (running, soccer, swimming, motocross, basketball) and had not been taking dietary supplements for a period of at least two months before the study. Participants were instructed not to change their training and dietary habits throughout the study.

\section{Study design}

This double-blind study with crossover design consisted of two experimental test days during which participants were randomly assigned to receive either $\mathrm{NaHCO}_{3}$ or placebo $(\mathrm{NaCl})$ with 
a 7-day wash-out period in between. The effect of stacked $\mathrm{NaHCO}_{3}$ loading was assessed in participants who performed four all-out cycling bouts throughout the day.

\section{Supplementation protocol}

All participants received $31.5 \mathrm{~g}$ of $\mathrm{NaHCO}_{3}$ (BIC) (which corresponded with an average relative dose of $0.43 \mathrm{~g} \cdot \mathrm{kg}^{-1} \mathrm{BM}$ ) in $700 \mathrm{mg}$ capsules spread over a 9-h period or an appearance-matched placebo (PL; $\mathrm{NaCl}$ ) containing an equimolar amount of sodium (see Fig. 1). Doses were administered in three 3-h cycles. Each cycle started with a $6.3 \mathrm{~g}$ dose administered with a light meal (850kcal; $62 \%$ carbohydrates, $16 \%$ proteins and $13 \%$ lipids), followed every hour by a $2.1 \mathrm{~g}$ dose in conjunction with $0.25 \mathrm{~L}$ water and a biscuit $(125 \mathrm{kcal})$ to facilitate uptake $(6)$.

\section{Study protocol}

The protocol consisted of four 2-min all-out cycling bouts interspersed by $3 \mathrm{~h}$ intervals. One week prior to the start of the experimental sessions, participants completed a familiarisation session to get habituated with isokinetic cycling on an electromagnetically braked cycle ergometer (Avantronic Cyclus II, Leipzig, Germany). During this session the optimal bike positioning settings were also determined. After a 10-min warm-up, a maximal isokinetic 2min bout was performed with a cadence fixed at 90rpm. On two following occasions, separated by one week, participants reported to the laboratory after an overnight fast and abstinence from severe exercise for at least 24-h. Every 3-h the following procedure was repeated: first, a $70 \mu 1$ capillary blood sample was taken from a preheated earlobe to determine blood $\left[\mathrm{HCO}_{3}^{-}\right]$and $\mathrm{pH}$

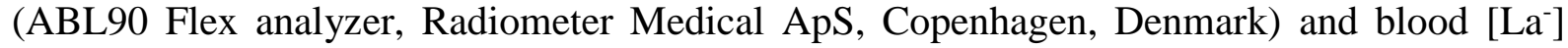
(Lactate Pro 2, Arkray, Japan). Subsequently, after a 10-min warm-up, a 2-min all-out cycling bout was performed during which the mean power output (MPO) was calculated. After 2-min of passive recovery, another capillary blood sample was taken, whereafter participants cooled down for 10-min at 100W. Finally, GI distress was assessed before participants consumed a standardized meal during which the sodium bicarbonate supplementation protocol was started (see above, Fig. 1). GI distress was assessed by a standardized questionnaire, quantifying systemic, upper abdominal and lower abdominal problems on a scale ranging from 0-8 (with 0 being 'no problem' and 8 being 'unbearable') and a maximal total score of 96 (adapted from Pfeiffer et al. 2009)(30). Ratings of perceived exertion (RPE) were recorded using the 15 point graded category scale of Borg(3).The exercise test sessions were conducted at the same time of the day for each participant to account for any possible circadian rhythm effects.

\section{Statistical analysis}

Values are presented as means \pm SEM. Differences in GI distress, in MPO and in blood [La-], $\left[\mathrm{HCO}_{3}{ }^{-}\right], \mathrm{pH}$ and their respective $\Delta$-values (=pre- $v s$. post-exercise) were analysed by a repeated measures ANOVA across conditions and time with a Bonferroni post-hoc test. Where relevant, Cohen's d was calculated as index of effect size (ES). Differences between values were considered to be significant for $\mathrm{P}<0.05$. Analyses were performed using $\mathrm{R}$ version 3.1 .2 ( $\mathrm{R}$ Foundation for Statistical Computing, Vienna, Austria).

\section{Results}

Acid-base balance (Fig. 2, Table 1) - Baseline blood $\mathrm{pH}$ and $\left[\mathrm{HCO}_{3}{ }^{-}\right]$were not significantly different between PL and BIC. In PL, because of the repetitive all-out bouts, pre-exercise $\mathrm{pH}$ and $\left[\mathrm{HCO}_{3}{ }^{-}\right]$(i.e. the respective blood values measured before the start of each bout) decreased and did not return to the resting levels before the start of the next cycling bout, so that there was an overall decline over time. In $\mathrm{BIC}$, pre-exercise $\mathrm{pH}$ and $\left[\mathrm{HCO}_{3}{ }^{-}\right]$gradually increased during the 9-h stacked loading period. Higher values in BIC than in PL were observed for $\Delta\left[\mathrm{HCO}_{3}{ }^{-}\right]$ 
and $\Delta\left[\mathrm{La}^{-}\right](\mathrm{P}<0.05$ for exercise bout 3 and 4$)$, yet $\Delta \mathrm{pH}$ was not significantly different between both conditions $(\mathrm{P}=0.49)$. In BIC, $\Delta\left[\mathrm{HCO}_{3}^{-}\right]$and $\Delta\left[\mathrm{La}^{-}\right]$gradually increased over time (bout 1 $<$ bout 3 and 4 , bout $2<$ bout $4 ; \mathrm{P}<0.05$ ).

All-out 2-min sprint performance (Fig. 3) - MPO on average was higher in BIC than in PL, i.e., $428 \pm 20 \mathrm{~W} v s .422 \pm 20 \mathrm{~W}(\mathrm{P}=0.035)$. The highest difference between conditions was observed in bout 3, where MPO was $\sim 3.2 \%$ higher in BIC. Furthermore, a significant time effect was observed with a higher MPO in bout 4 than in bout $2(\mathrm{P}=0.021)$.

Gastrointestinal symptoms - Most participants scored the majority of their GI symptoms at the low end of the scale ('no problem' - 'very minor problems'). Unexpectedly, the total GI distress score (sum of the registration moments) was elevated in PL compared to BIC, i.e. 13.5 $\pm 5.6 \mathrm{vs}$. $4.7 \pm 1.8(\mathrm{P}=0.047)$. This could mainly be explained by one outlier in PL, which reported flatulence, vomiting and diarrhea. After exclusion of this outlier, the GI distress score decreased to $8.2 \pm 1.9$ in PL, which is considered as 'low GI distress'.

\section{Discussion}

This is the first study to test the ergogenicity of a 9-h stacked $\mathrm{NaHCO}_{3}\left(0.4 \mathrm{~g} \cdot \mathrm{kg}^{-1} \mathrm{BM}\right)$ loading protocol during which repeated all-out exercise bouts throughout the day are performed. We demonstrate that such a gradual loading strategy improves repetitive all-out exercise in the absence of GI distress, despite the total dose being higher than the prevailing recommendation of $0.3 \mathrm{~g} \mathrm{~kg}^{-1} \mathrm{BM}$. The advantage of this loading protocol is that blood $\mathrm{HCO}_{3}^{-}$levels remained elevated throughout the day.

Blood $\mathrm{HCO}_{3}{ }^{-}$levels gradually increased by $\sim 6 \mathrm{mmol} \cdot \mathrm{L}^{-1}(+23 \%)$ during the 9-h loading period, which is $\sim 2 \mathrm{mmol} \cdot \mathrm{L}^{-1}$ higher than values reported following a single $0.3 \mathrm{~g} \cdot \mathrm{kg}^{-1} \mathrm{BM} \mathrm{NaHCO}$ dose (see Carr et al. (2011))(8). Also, the decrement of blood $\left[\mathrm{HCO}_{3}{ }^{-}\right]$and increase of blood $\left[\mathrm{La}^{-}\right]$were higher in BIC than in PL, suggesting that there was a facilitated co-transport of $\mathrm{H}^{+}$ and $\mathrm{La}^{-}$out of the muscle cell during each cycling bout. Alternatively, the higher post-exercise blood [ $\left.\mathrm{La}^{-}\right]$in BIC might be due to reduced $\mathrm{La}^{-}$clearance, as it was reported that $\mathrm{La}^{-}$clearance by inactive skeletal muscle tissue is reduced following $\mathrm{NaHCO}_{3}$ supplementation(17). In contrast to $\Delta\left[\mathrm{HCO}_{3}{ }^{-}\right]$and $\Delta\left[\mathrm{La}^{-}\right]$, the exercise-induced drop in blood $\mathrm{pH}$ was similar between BIC and PL, despite higher pre-exercise $\mathrm{pH}$ values in BIC, which is in agreement with other studies $(20,33,35)$. The similar drop in $\mathrm{pH}$ during exercise in both conditions seems contra intuitive. However, the Henderson-Hasselbalch equation states that blood $\mathrm{pH}$ depends on the ratio between $\left[\mathrm{HCO}_{3}{ }^{-}\right]$and $\mathrm{pCO}_{2}$. Prior to exercise, the higher $\mathrm{pH}$ values in $\mathrm{BIC}$ could be explained by elevated $\left[\mathrm{HCO}_{3}^{-}\right]$, while the $\mathrm{pCO}_{2}$ probably remained relatively unchanged since very little $\mathrm{HCO}_{3}{ }^{-}$was used at rest. During the exercise bouts, the drop in $\left[\mathrm{HCO}_{3}{ }^{-}\right]$was larger in BIC than in PL. Given that the drop in $\mathrm{pH}$ was similar between both conditions, the drop in $\mathrm{pCO}_{2}$ must have been higher in BIC compared to PL. Indeed, unpublished observations in our group showed that $\Delta \mathrm{pCO}_{2}$ following an all-out running bout $( \pm 100 \mathrm{~s})$ in $\mathrm{BIC}(5.3 \pm 1.3 \mathrm{mmHg})$ tended to be higher than in PL $(3.5 \pm 1.1 \mathrm{mmHg}$; $\mathrm{p}=0.11)$.

In quite a number of sports disciplines the competition schedule involves repetitive all-out exercise bouts to be performed throughout the day. Therefore, in the present study, four 2-min all-out exercise bouts with 3-h recovery intervals in between were used to evaluate the ergogenic potential of a novel stacked $\mathrm{NaHCO}_{3}$ supplementation protocol. Interestingly, our results showed that $\mathrm{NaHCO}_{3}$ supplementation significantly enhanced performance in 2-min allout cycling bouts following both 6-h (+3.2\%; ES: 0.20) and 9-h (+1.7\%; ES: 0.10$)$ of stacked 
supplementation, but not in the earlier bouts. This is not surprising since less than $0.2 \mathrm{~g} \mathrm{NaHCO}_{3}$ per kg BM was administered prior to bouts 1 (ES: 0.03) and 2 (ES: 0.03), which is too low to generate an ergogenic effect(26). Improved performance upon 6-h supplementation is interesting in a number of sport disciplines in which multiple competitions are scheduled during the day. It should be noted, however, that our participants were not elite athletes. Still, this does not exclude that our findings may be extrapolated to the elite. In fact, we extensively applied this protocol 'in the field' in a number of world-class track cyclists during omnium competition. These athletes experienced no GI discomfort at all, and generally performed well. One of the athletes set a new personal best on the $4 \mathrm{~K}$ individual pursuit. Additionally, in their metaanalysis, Carr et al.(8) indicated that the inclusion of non-athletes had a small detrimental effect on the $\mathrm{NaHCO}_{3}$-induced performance benefits. Unpublished data from our lab revealed that elite cyclists improved their 90s sprint performance to the same degree as in the current study. We therefore believe that the proposed supplementation protocol can be used in multiple competition contexts. For instance, in the omnium competition in track cycling, riders often participate in 4 events in one day (i.e. a scratch, elimination, tempo race, points race), but also in other sports disciplines such as swimming, judo, athletics, multiple qualification rounds are spread over the day, with medal events taking place in the evening. Athletes and coaches ought to consider the administration of (small) $\mathrm{NaHCO}_{3}$ doses in between intermittent severe exercise bouts, taking into account 1) the personal preferences/GI sensitivity of the athlete, 2) the type of exercise and 3) the recovery time in between different bouts.

The effect of $\mathrm{NaHCO}_{3}$ supplementation on intermittent short all-out cycling bouts was demonstrated in previous $\operatorname{work}(2,9,21,23,27,28,37,38)$. However, in these studies the intermittent exercise protocol lasted 30-min or less, whilst in the present study, exercise bouts were spread over a 9-h period with 3-h intervals in between, which from a metabolic perspective is an entirely different situation. In short intermittent exercise the contribution of glycolytic ATP production gradually decreases as the number of exercise bouts increases(14). Conversely, repeated all-out exercise bouts with 3-h intervals in between allow for a higher glycolytic flux in each single bout, since intermediates and key enzymes of the anaerobic glycolysis are (partly) restored during the recovery time(19). Also, in none of the previous studies, $\mathrm{NaHCO}_{3}$ was supplemented in between the all-out cycling bouts, which might explain why sometimes no ergogenic effect of sodium bicarbonate supplementation was observed. For instance, Zabala et al. (2011) supplemented $0.3 \mathrm{~g} \cdot \mathrm{kg}^{-1} \mathrm{BM} 90$-min prior to the first of three 30 -s all-out cycling sprints, with 15-min recovery in between(37). While blood $\mathrm{HCO}_{3}{ }^{-}$levels significantly increased prior to sprint 1 (i.e. from $\sim 24.5$ to $28.5 \mathrm{mmol} \cdot \mathrm{L}^{-1}$ ), the pre-exercise $\left[\mathrm{HCO}_{3}{ }^{-}\right]$decreased below baseline levels at the start of sprint $2\left(\sim 18 \mathrm{mmol} \cdot \mathrm{L}^{-1}\right)$ and sprint $3\left(\sim 14.5 \mathrm{mmol} \cdot \mathrm{L}^{-1}\right)$. Future studies should therefore reveal whether small $\mathrm{NaHCO}_{3}$ doses ingested during the rest interval between short maximal exercise bouts might improve pre-exercise buffering capacity, and thereby performance, in particular when the recovery time is relatively short (e.g. 15min).

Although it was previously reported that GI distress aggravates with acute $\mathrm{NaHCO}_{3}$ doses exceeding $0.3 \mathrm{~g} \mathrm{~kg}^{-1} \mathrm{BM}(26)$, our stacked $\mathrm{NaHCO}_{3}$ loading did not increase GI complaints, despite $0.4 \mathrm{~g} \mathrm{~kg}^{-1} \mathrm{BM} \mathrm{NaHCO}_{3}$ being administered over a 9-h period. Conversely, GI complaints were higher in PL than in BIC. However, this difference was due to one participant who reported upper GI distress both after the first and the second meal, and another participant with the same complaints after the last meal. None of these complaints were reported in BIC. The placebo capsules were identical to the capsules used in BIC, and were filled with an equimolar amount of $\mathrm{Na}^{+}(2)$. Therefore, it is very unlikely that differences in upper GI complaints were due to $\mathrm{Na}^{+}$-induced disturbances. The particular reason for the differences in GI distress between both conditions is unclear. However, the most likely explanation is the more severe 
exercise-induced acidosis in PL. The average post-exercise $\mathrm{pH}$ was 0.05 lower in BIC than in PL (7.23 \pm 0.02 vs. $7.18 \pm 0.01$, respectively). Following a performance predominantly relying on anaerobic glycolysis, systemic acidosis may cause vomiting as a physiological response to drain $\mathrm{H}^{+}$and thereby allow the stomach to add bicarbonate to the body(34). Despite the GI problems in PL, we assume that this did not affect performance as the participants with higher GI distress exhibited similar maximal [ $\left.\mathrm{La}^{-}\right], \mathrm{RPE}$ and performance compared to participants with minimal GI symptoms. Besides the implementation of a stacked loading strategy, we also tried to minimise GI distress by loading $\mathrm{NaHCO}_{3}$ via capsules. In recent studies, Gough et al. (2017, 2018) and Freis et al. (2017) reported substantial GI discomfort following the intake of $0.3 \mathrm{~g} \mathrm{~kg}^{-}$ ${ }^{1} \mathrm{BM} \mathrm{NaHCO} 3$ when dissolved in a solution $(13,15,16)$. The authors suggested that the hypertonic $\mathrm{NaHCO}_{3}$ solution might have resulted in excess fluid retention into the GI tract, which is likely to induce diarrhea(13). Furthermore, Breitkreutz et al. (2007) mentioned that $\mathrm{NaHCO}_{3}$ released in the acid environment of the stomach is transformed into carbon dioxide, causing abdominal pain and flatulence, and limiting its ergogenic potential(4). These incidents can be reduced by using capsules to postpone the release of $\mathrm{NaHCO}_{3}$ to the small intestine, with minimal interference at the level of the stomach and thus less upper GI distress.

It is the prevailing opinion that the optimal time for $\mathrm{NaHCO}_{3}$ administration is 60-90-min prior to exercise(24). Miller et al. (2016) observed that, in most of their participants, pH peaked between 60 and 90-min after ingestion of a single dose of $0.3 \mathrm{~g} \mathrm{~kg}^{-1} \mathrm{BM} \mathrm{NaHCO}$. They proposed this time to reach peak blood $\mathrm{pH}$ as the optimal time delay where the highest ergogenic effect might be expected(27). However, one should keep in mind that participants might also suffer from GI distress 60-90-min after consumption of $\mathrm{NaHCO}_{3}(27)$, which might impair the beneficial effects of the induced alkalosis. Therefore, the stacked loading strategy applied here, may be a more effective approach to supplement a similar or even higher dose of $\mathrm{NaHCO}_{3}$ in the absence of GI distress. Furthermore, such loading strategy extends the plateauing of peak blood $\left[\mathrm{HCO}_{3}{ }^{-}\right]$providing a prolonged time window of ergogenicity.

\section{Conclusion}

The main finding of this study is that $0.4 \mathrm{gkg}^{-1} \mathrm{BM} \mathrm{NaHCO}_{3}$, gradually supplemented over a 9$\mathrm{h}$ time period, improved all-out performance in the absence of significant GI symptoms. Besides its ergogenic effect, the protocol is time effective since there is no need to predetermine the individualized time to peak $\mathrm{HCO}_{3}{ }^{-}$due to a sustained increase in blood bicarbonate. The proposed stacked loading strategy could be recommended in a variety of sports disciplines with multiple qualification rounds throughout the day. However, athletes and coaches should still take into account the competition schedule and the athlete's tolerance to $\mathrm{NaHCO}_{3}$ to determine the appropriate loading strategy.

\section{References}

1. Bangsbo J, Madsen K, Kiens B, Richter EA. Effect of muscle acidity on muscle metabolism and fatigue during intense exercise in man. $J$ Physiol 1996;495:587-96.

2. Bishop D, Edge J, Davis C, Goodman C. Induced metabolic alkalosis affects muscle metabolism and repeated-sprint ability. Med Sci Sport Exerc 2004;36:807-13.

3. Borg G. Perceived exertion as an indicator of somatic stress . Scand J Rehabil Med 1970;2:92-8.

4. Breitkreutz J, Gan TG, Schneider B, Kalisch P. Enteric-coated solid dosage forms containing sodium bicarbonate as a drug substance: an exception from the rule? $J$ Pharm Pharmacol 2007;59:59-65.

5. Bruton JD, La JAN, Joseph D, La J. Effects of CO2 -induced acidification on the 
fatigue resistance of single mouse muscle fibers at $28^{\circ} \mathrm{C}$. J Appl Physiol 1998;85:478483.

6. Burke LM. Practical considerations for bicarbonate loading and sports performance. Nestle Nutr Inst Workshop Ser 2013;75:15-26.

7. Burke LM, Pyne DB. Bicarbonate loading to enhance training and competitive performance. Int J Sports Physiol Perform 2007;2:93-7.

8. Carr AJ, Hopkins WG, Gore CJ. Effects of acute alkalosis and acidosis on performance: A meta-analysis. Sport Med 2011;41:801-14.

9. Costill D, Verstappen F, Kuipers H, Jansson E, Fink W. Acid-base balance during repeated bouts of exercise: influence of HCO3. Med Sci Sport Exerc 1983;15:115-115.

10. Degroot M, Massie BM, Boska M, Gober J, Miller RG, Weiner MW. Dissociation of $[\mathrm{H}+]$ from fatigue in human muscle detected by high time resolution 31P-NMR. Muscle Nerve 1993;16:91-8.

11. Edge J, Bishop D, Goodman C. Effects of chronic NaHCO3 ingestion during interval training on changes to muscle buffer capacity, metabolism, and short-term endurance performance. J Appl Physiol 2006;101:918-25.

12. Fitts RH. Cellular mechanisms of muscle fatigue. Physiol Rev 1994;74:49-94.

13. Freis T, Hecksteden A, Such U, Meyer T. Effect of sodium bicarbonate on prolonged running performance: A randomized, double- blind, cross-over study. PLoS One 2017; 12:e0182158.

14. Gaitanos G, Williams C, Boobis L, Brooks S. Human muscle metabolism maximal exercise. J Appl Physiol 1993;75:712-9.

15. Gough LA, Deb SK, Sparks AS, Mcnaughton LR. The reproducibility of blood acid base responses in male collegiate athletes following individualised doses of sodium bicarbonate: A randomised controlled crossover study. Sport Med 2017;47:2117-27.

16. Gough LA, Deb SK, Sparks SA, Mcnaughton LR. Sodium bicarbonate improves 4 km time trial cycling performance when individualised to time to peak blood bicarbonate in trained male cyclists individualised to time to peak blood bicarbonate in trained male cyclists. J Sports Sci 2018;36:1705-12.

17. Granier PL, Dubouchaud H, Mercier BM, Mercier JG, Ahmaidi S, Préfaut CG. Effect of $\mathrm{NaHCO} 3$ on lactate kinetics in forearm muscles during leg exercise in man. Med Sci Sport Exerc 1996;28:692-7.

18. Harriss D, Macsween A, Atkinson G. Standards for Ethics in Sport and Exercise Science Research: 2018 Update. Int J Sport Med 2017;38:1126-31.

19. Krause U, Wegener G. Control skeletal of glycolysis in vertebrate muscle during exercise. Am J Physiol Regul Integr Comp Physiol 1996;270:R821-9.

20. Kupcis PD, Slater GJ, Pruscino CL, Kemp JG. Influence of sodium bicarbonate on performance and hydration in lightweight rowing. Int J Sport Physiol Perform 2012;7:11-8.

21. Lavender G, Bird SR. Effect of sodium bicarbonate ingestion upon repeated sprints. $\mathrm{Br}$ J Sport Med 1989;23:41-5.

22. Mainwood G, Worsmey-Brown P. The effects of extracellular $\mathrm{pH}$ and buffer concentration on the efflux of lactate from frog sartorius muscle. $J$ Physiol 1975;250:122.

23. Mckenzie DC, Coutts KD, Stirling DR, Hoeben HH, Kuzara G. Maximal work production following two levels of artificially induced metabolic alkalosis. J Sport Sci 1986;4:35-8.

24. Mcnaughton L, Backx K, Palmer G, Strange N. Effects of chronic bicarbonate ingestion on the performance of high-intensity work. Eur J Appl Physiol 1999;80:3336. 
25. McNaughton L, Curtin R, Goodman G, Perry D, Turner B, Showell C. Anaerobic work and power output during cycle ergometer exercise: effects of bicarbonate loading. $J$ Sport Sci 1991;9:151-60.

26. McNaughton LR. Bicarbonate ingestion: effects of dosage on 60 s cycle ergometry. $J$ Sport Sci 1992;10:415-23.

27. Miller P, Robinson AL, Sparks SA, Bridge CA, Bentley DJ, McNaughton LR. The effects of novel ingestion of sodium bicarbonate on repeated sprint ability. J Strength Cond Res 2016;30:561-8.

28. Mündel T. Sodium bicarbonate ingestion improves repeated high-intensity cycling performance in the heat. Temperature 2018;1-5.

29. Nelson CR, Fitts RH. Effects of low cell $\mathrm{pH}$ and elevated inorganic phosphate on the pCa-force relationship in single muscle fibers at near-physiological temperatures. Am J Physiol Cell Physiol 2014;306:C670-8.

30. Pfeiffer B, Cotterill A, Grathwohl D, Stellingwerff T, Jeukendrup AE. The effect of carbohydrate gels on gastrointestinal tolerance during a 16-km run. Int J Sport Nutr Exerc Metab 2009;19:485-503.

31. Sahlin K. Muscle fatigue and lactic acid accumulation. Acta Physiol Scand Suppl 1986;556:83-91.

32. Saunders B, Sale C, Harris RC, Sunderland C. Sodium Bicarbonate and High-IntensityCycling Capacity: Variability in Responses. Int J Sports Physiol Perform 2014;9:62732.

33. Siegler J, Gleadall-Siddall D. Sodium bicarbonate ingestion and repeated swim sprint performance. J Strength Cond Res 2010;24:3105-11.

34. Valeur J, Julsrud J. Vomiting: a physiological response to acidosis? Scand J Gastroenterol 2013;48:1103-4.

35. Vanhatalo A, McNaughton LR, Siegler J, Jones AM. Effect of induced alkalosis on the power-duration relationship of "all-out" exercise. Med Sci Sports Exerc 2010;42:56370 .

36. Westerblad H. Acidosis is not a significant cause of skeletal muscle fatigue. Med Sci Sport Exerc 2016;48:2339-42.

37. Zabala M, Peinado AB, Calderon FJ, Sampedro J, Castillo MJ, Benito PJ. Bicarbonate ingestion has no ergogenic effect on consecutive all out sprint tests in BMX elite cyclists. Eur J Appl Physiol 2011;111:3127-34.

38. Zabala M, Requena B, Sanchez-Munoz C, et al. Effects of sodium bicarbonate ingestion on performance and perceptual responses in a laboratory-simulated BMX cycling qualification series. J Strength Cond Res 2008;22:1645-53. 


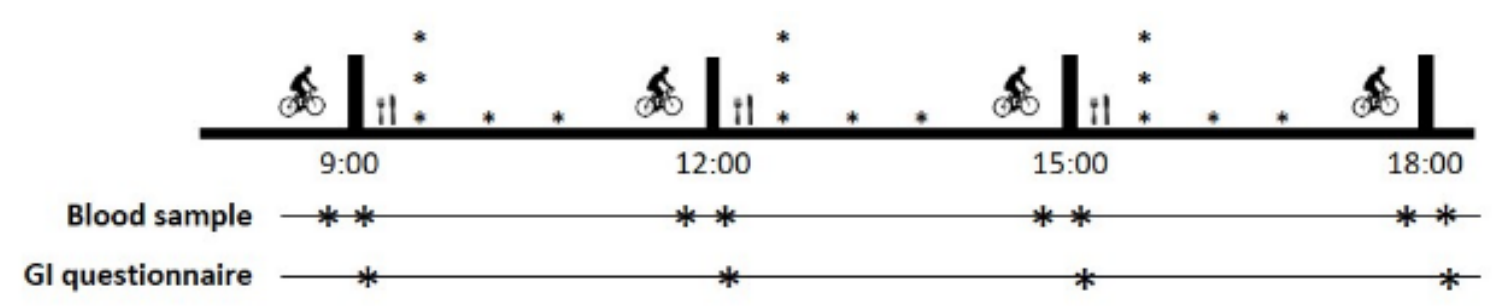

Figure 1. Schematic presentation of the study protocol.

Participants $(n=12)$ performed 4 all-out cycling bouts over a 9-h time window. They received sodium bicarbonate or placebo in a randomised double-blind cross-over design. Every 3-h, a $6.3 \mathrm{~g}$ dose $(* * *)$ with standardized meal (闬) was followed by 2 smaller dosages of $2.1 \mathrm{~g}(*)$. Capillary blood samples and a questionnaire for gastrointestinal (GI) side-effects were taken at regular intervals.
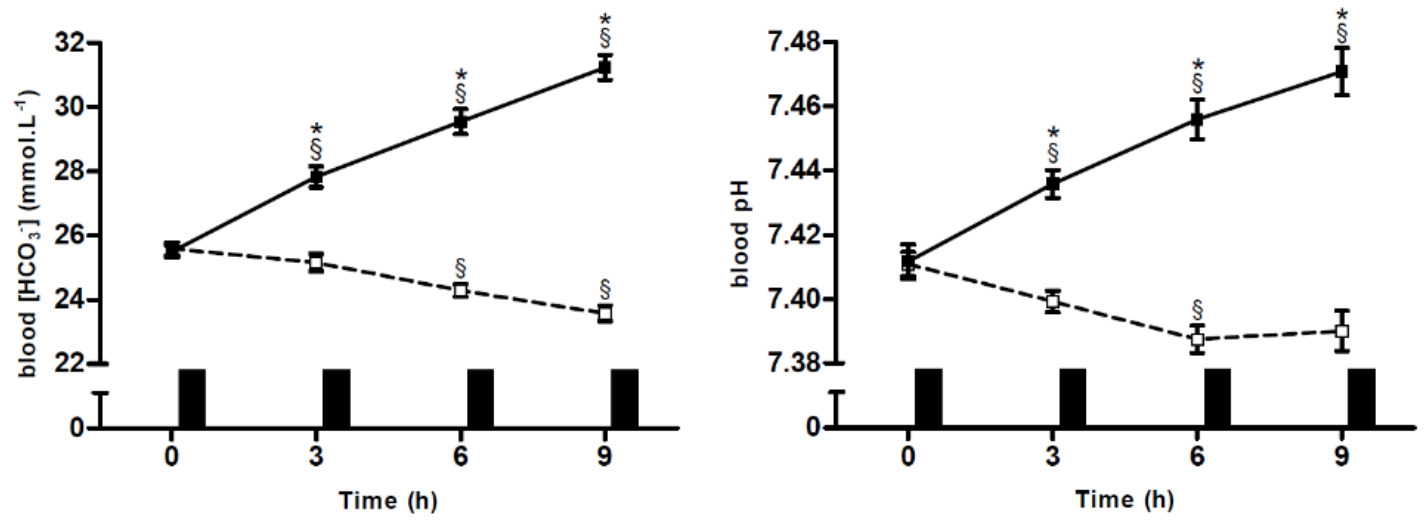

Figure 2. Effects of sodium bicarbonate intake on blood acid-base balance.

Data are mean \pm SEM $(n=12)$ for blood bicarbonate (left panel) and blood $\mathrm{pH}$ (right panel) before the start of a 2-min all-out exercise bout after 0,3,6 and 9-h of supplementation with either placebo ( $\square$ ) or sodium bicarbonate ( $\square)$. The black vertical bars represent the 2-min allout exercise bouts. * $\mathrm{P}<0.05$ compared with PL. $\S \mathrm{P}<0.05$ compared with baseline $(0 \mathrm{~h})$.

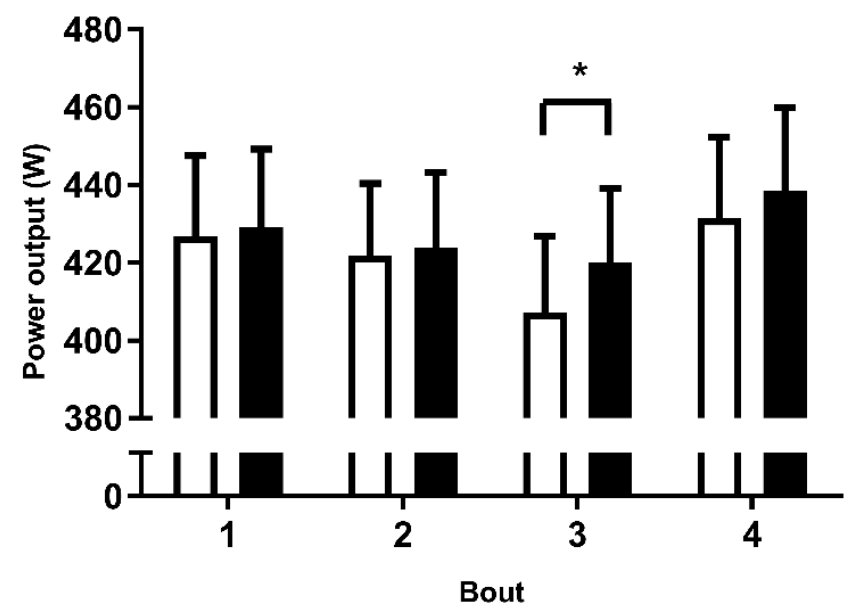

Figure 3. Effects of sodium bicarbonate intake on performance.

Data are mean $\pm \operatorname{SEM}(n=12)$ for mean power output of the 4 cycling bouts after $0,3,6$ and 9$\mathrm{h}$ of supplementation with either placebo $(\square)$ or sodium bicarbonate $(\mathbf{\square}){ }^{*} \mathrm{P}<0.05$ compared with PL. 


\begin{tabular}{|c|c|c|c|c|c|c|c|c|c|c|}
\hline & & \multicolumn{3}{|c|}{ PL } & \multicolumn{3}{|c|}{$\mathrm{BIC}$} & \multicolumn{3}{|c|}{$\mathrm{ES}$} \\
\hline & & $\begin{array}{c}\mathrm{HCO}_{3}^{-} \\
\left(\mathrm{mmol} \cdot \mathrm{L}^{-1}\right)\end{array}$ & $\mathrm{pH}$ & $\begin{array}{c}\mathrm{La}^{-} \\
\left(\mathrm{mmol} \cdot \mathrm{L}^{-1}\right)\end{array}$ & $\begin{array}{c}\mathrm{HCO}_{3}^{-} \\
\left(\mathrm{mmol} \cdot \mathrm{L}^{-1}\right)\end{array}$ & $\mathrm{pH}$ & $\begin{array}{c}\mathrm{La}^{-} \\
\left(\mathrm{mmol} \cdot \mathrm{L}^{-1}\right)\end{array}$ & $\mathrm{HCO}_{3}^{-}$ & $\mathrm{pH}$ & $\mathrm{La}^{-}$ \\
\hline \multirow[t]{2}{*}{ Bout 1} & Pre & $25.6 \pm 0.2$ & $7.41 \pm 0.00$ & $1.0 \pm 0.1$ & $25.5 \pm 0.2$ & $7.41 \pm 0.01$ & $0.9 \pm 0.1$ & 0.12 & 0.00 & 0.30 \\
\hline & Post & $14.1 \pm 0.3$ & $7.19 \pm 0.01$ & $10.3 \pm 0.5$ & $13.9 \pm 0.4$ & $7.17 \pm 0.01$ & $9.7 \pm 0.6$ & 0.21 & 0.37 & 0.32 \\
\hline \multirow[t]{2}{*}{ Bout 2} & Pre & $25.2 \pm 0.3$ & $7.40 \pm 0.00$ & $1.1 \pm 0.1$ & $27.8 \pm 0.3 * \S$ & $7.43 \pm 0.00 * \S$ & $1.2 \pm 0.1$ & 1.56 & 1.54 & 0.18 \\
\hline & Post & $14.2 \pm 0.4$ & $7.19 \pm 0.01$ & $10.3 \pm 0.6$ & $15.7 \pm 0.4 * \S$ & $7.23 \pm 0.01 * \S$ & $11.5 \pm 0.4 * \S$ & 0.97 & 1.04 & 0.71 \\
\hline \multirow[t]{2}{*}{ Bout 3} & Pre & $24.3 \pm 0.2 \S$ & $7.39 \pm 0.00$ & $0.9 \pm 0.0$ & $29.5 \pm 0.4 * \S$ & $7.46 \pm 0.01 * \S$ & $1.0 \pm 0.1$ & 1.82 & 1.76 & 0.43 \\
\hline & Post & $14.0 \pm 0.6$ & $7.18 \pm 0.02$ & $10.2 \pm 0.9$ & $16.3 \pm 0.5 * \S$ & $7.26 \pm 0.01 * \S$ & $12.6 \pm 0.4 * \S$ & 1.01 & 1.22 & 0.94 \\
\hline \multirow[t]{2}{*}{ Bout 4} & Pre & $23.6 \pm 0.2 \S$ & $7.39 \pm 0.01$ & $0.9 \pm 0.1$ & $31.2 \pm 0.4 * \S$ & $7.47 \pm 0.01 * \S$ & $0.9 \pm 0.1$ & 1.88 & 1.71 & 0.09 \\
\hline & Post & $13.2 \pm 0.3$ & $7.17 \pm 0.01$ & $11.0 \pm 0.4$ & $16.8 \pm 0.6 * \S$ & $7.27 \pm 0.02 * \S$ & $13.1 \pm 0.5 * \S$ & 1.48 & 1.33 & 1.10 \\
\hline
\end{tabular}

Table 1. Blood bicarbonate, pH and lactate pre and post each all-out cycling bout.

Data are mean \pm SEM $(\mathrm{n}=12)$ for blood bicarbonate $\left(\mathrm{HCO}_{3}{ }^{-}\right)$, $\mathrm{pH}$ and lactate $\left(\mathrm{La}^{-}\right)$for each 2-min all-out exercise bout after 0, 3, 6 and 9-h of supplementation with either placebo or sodium bicarbonate. $\mathrm{ES}=$ the Cohen's d effect size for all blood parameters. * $\mathrm{P}<0.05$ compared with PL. $\S \mathrm{P}<0.05$ compared with baseline (0-h). All $\mathrm{HCO}_{3}{ }^{-}, \mathrm{pH}$ and $\mathrm{La}^{-}$values significantly differed between pre and post for every exercise bout, but for clarity reasons this is not indicated in the table. 